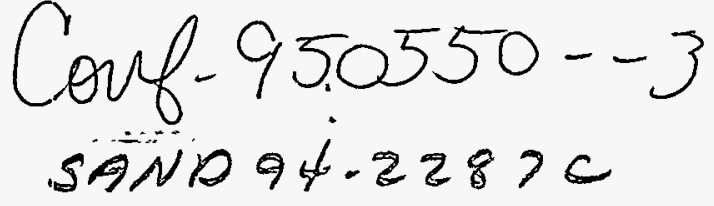

\title{
MARS PATHFINDER AIRBAG IMPACT ATTENUATION SYSTEM*
}

\author{
Donald E. Waye† and J. Kenneth Coleł \\ Sandia National Laboratories§ \\ Albuquerque, NM 87185
}

\section{$\underline{\text { Abstract }}$}

The Mars Pathfinder spacecraft, scheduled for launch in November 1996, is designed to validate a low cost Entry, Descent, and Landing system and to perform scientific surface operations. The Jet Propulsion Laboratory and Sandia National Laboratories teamed to design, fabricate, test and validate a prototype 0.38 scale model of an airbag impact attenuation system.

A computer code was developed to predict the performance of the airbag system. A test program in Sandia's High Altitude Chamber was performed to validate the code and demonstrate the feasibility of the airbag concept and design. In addition, freefall tests were performed at representative velocities to demonstrate the structural integrity of the airbag system design. The feasibility program demonstrated that the airbag impact attenuation design will protect the lander upon impact with the Martian surface.

\section{Nomenclature}

$\begin{array}{ll}\text { a } & \text { linear acceleration of payload }\left(\mathrm{m} / \mathrm{s}^{2}\right) \\ \mathrm{a}^{*} & \text { speed of sound in gas }(\mathrm{m} / \mathrm{s}) \\ \mathrm{A} & \text { area }\left(\mathrm{m}^{2}\right) \\ \mathrm{A}_{\mathrm{FP}} & \text { area of bottom bag footprint }\left(\mathrm{m}^{2}\right) \\ \mathrm{g}_{\mathrm{Mars}} & \text { acceleration of gravity on } \mathrm{Mars}\left(\mathrm{m} / \mathrm{s}^{2}\right) \\ \mathrm{k} & \text { discharge coefficient for an orifice } \\ \mathrm{m} & \text { mass of the payload }(\mathrm{kg}) \\ \mathrm{n} & \text { pressure ratio for scaling }\end{array}$

- This work sponsored by Jet Propulsion Laboratory, California Institute of Technology, Pasadena, CA under project NASA DPR WO-9004.

$\dagger$ Senior Member of Technical Staff, Fluid/Structure Interactions Department, Senior Member of AIAA.

$\ddagger$ Senior Member of Technical Staff, Thermophysics Department, Associate Fellow of AIAA.

I Member of Technical Staff, Mechanical System Development Section, Member of AIAA.

\$ This work performed at Sandia National Laboratories supported by the U.S. Department of Energy under contract number DE-AC0494AL85000.

This paper is declared a work of the U.S. Government and is not subject to copyright protection in the United States

\author{
Tommaso P. Rivelliniף \\ Jet Propulsion Laboratory \\ California Institute of Technology \\ Pasadena, CA 91109
}

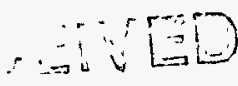

M Mach number

p pressure (Pascals, newtons $/ \mathrm{m}^{2}$ )

$\mathrm{R}_{\mathrm{GAS}} \quad$ gas constant (Joules $/ \mathrm{kg} \mathrm{K}$ )

$\mathrm{T}$ gas temperature $(\mathrm{K})$

$t$ time (seconds)

$\mathrm{u} \quad$ velocity of gas $(\mathrm{m} / \mathrm{s})$

$\mathrm{U}$ velocity of the payload $(\mathrm{m} / \mathrm{s})$

$\mathrm{V}$ volume $\left(\mathrm{m}^{3}\right)$

W mass of gas contained in airbag $(\mathrm{kg})$

$x \quad$ distance $(\mathrm{m})$

$\gamma \quad$ ratio of specific heats, $\left(\mathrm{C}_{\mathrm{p}} / \mathrm{C}_{\mathrm{v}}\right), 1.4$ for $\mathrm{N}_{2}$

$\lambda$ geometric scaling factor

$\rho$ density of: gas $\left(\mathrm{kg} / \mathrm{m}^{3}\right)$

\section{Introduction}

The Mars Pathfinder spacecraft, scheduled to be launched in November 1996, will be the first lander launched to Mars since the Viking missions in the early 1970's. This mission, the first of a series of low cost Discovery class missions, is a "pathfinder" for NASA's engineering design methodology of "faster, better, cheaper." The mission is designed to demonstrate and validate a low cost Entry, Descent, and Landing (EDL) system and to perform state-of-the-art scientific surface operations. The Entry and Descent designs are based on the Viking lander heat shield and parachute designs, respectively. The Landing portion of the spacecraft consists of a bridal mounted retro-rocket system and an airbag impact attenuation system.

The Jet Propulsion Laboratory teamed with Sandia National Laboratories to design, fabricate, test, and validate a 0.38 scale prototype airbag impact attenuation system as a proof of concept for the Pathfinder spacecraft. This paper will describe the airbag design, the computer model used for predicting airbag performance, and the tests conducted at Sandia in the High Altitude Chamber and the Coyote Canyon Test Facility. The airbags and tests were designed to validate the computer model as well as to demonstrate the structural integrity and dynamic characteristics of the system. 


\section{DISCLAIMER}

This report was prepared as an account of work sponsored by an agency of the United States Government. Neither the United States Government nor any agency therieof, nor any of their employees, make any warranty, express or implied, or assumes any legal liability or responsibility for the accuracy, completeness, or usefulness of any information, apparatus, product, or process disclosed, or represents that its use would not infringe privately owned rights. Reference herein to any specific commercial product, process, or service by trade name, trademark, manufacturer, or otherwise does not necessarily constitute or imply its endorsement, recommendation, or favoring by the United States Government or any agency thereof. The views and opinions of authors expressed herein do not necessarily state or reflect those of the United States Government or any agency thereof. 


\section{DISCLAIMER}

Portions of this document may be illegible in electronic image products. Images are produced from the best available original document. 


\section{Concepts}

Several concepts were examined for the descent and landing phase of the Pathfinder mission. A system, modeled on the Viking system, with rockets actively controlling the vertical and horizontal components of velocity was considered. This system would have required complex components which became impractical given the schedule and budget available.

The driving design parameters were that the lander be able to deploy a rover onto the surface and also take a panoramic picture of the surface. Equally as important was that the lander not experience more than $50 \mathrm{~g}$ 's deceleration on impact. The decision was made to use an inflatable impact attenuation system that could tolerate both vertical and horizontal velocities on impact. Since the horizontal velocity component at impact was estimated to be quite severe, a system with omni-directional impact capability was required.

Spherical airbags were considered. Their downfall was that the inflatable membrane completely surrounds the payload and the task of deploying the rover and instruments becomes very complex. Systems where multiple spherical airbags were simply clustered around the payload proved to be very inefficient. Non-spherical airbags of various geometric shapes were also considered and ruled out since they were structurally inefficient. The configuration selected consists of a tetrahedral lander with an airbag on each of its four sides. Each airbag is made up of spherical lobes merged together to form a single larger volume. The airbags are tethered to the lander via structural tendons integrated into each airbag. The system is inflated with hot gas generators approximately 3-8 seconds prior to impact.

The tetrahedral lander with four individual airbags allows access to the lander when the airbags deflate after the impact event. The rover and the scientific instrumentation are subsequently deployed by folding out three of the four tetrahedron panels, like a flower blossoming. This "self righting" method of opening eliminates the requirement to control the orientation of the lander as it comes to rest after landing. With the basic concept selected, the task of designing the airbags became a function of the actual impact conditions.

\section{Impact Environment}

The surface ambient conditions for the landing sites under consideration include a nighttime temperature of approximately $-75^{\circ} \mathrm{C}$ and a pressure of approximately $1 \mathrm{kPa}$ (about 1/100 that of Earth). Due to this rarefied atmosphere, a practically sized parachute can only decelerate the spacecraft to a terminal velocity of about $35 \mathrm{~m} / \mathrm{s}$. Previously collected data indicate that 90th percentile surface winds are approximately $35 \mathrm{~m} / \mathrm{s}$. These winds, combined with the vertical velocity, create a maximum impact velocity of $50 \mathrm{~m} / \mathrm{s}$ at an angle of $45^{\circ}$. Rocks at the landing sites are predicted to be about 0.5 meters high.

\section{Airbag Design}

The original airbag design concept was derived from the "airbag impact attenuator" work performed at JPL in the mid 1960's [1]. The fundamental concept, which is that of a "lumpy" sphere, implies a high elastic modulus inflatable membrane with preloaded tendons. The tendons are used to transfer the pneunatic load from the membrane to the rigid body being decelerated.

\section{Basic Sizing}

The first generation Pathfinder airbag was sized to decelerate a $230 \mathrm{~kg}$ lander from $35 \mathrm{~m} / \mathrm{s}$ to zero and limit the lander deceleration to less than $\mathbf{5 0}$ g's. The first consideration in sizing the airbags was to determine the required deceleration stroke. Assuming a constant deceleration the required stroke is $\mathbf{1 . 2 5}$ meters. The mission requirement to survive impact on 0.5 meter rocks brings the minimum allowable airbag height to 1.75 meters.

Load transfer was maximized by minimizing relative movement between the airbag system and the lander. This was done by sizing and spacing the lobes of the airbags such that the center to center distance between any two adjacent lobes in the entire system is identical. Figure 1 shows the geometry for an airbag with three lobes, each with a radius of 1.2 meters and a lobe to lobe spacing of 1.92 meters. A single airbag is composed of three spherical lobes as seen from the outside. Internally, however, the airbag is one open volume with no internal membranes or septums. Figure 2 shows the geometry of the entire airbag system. 
Once the basic configuration was selected, analyses were performed to characterize the performance. Internal vents were added to allow the "bottom" bag to vent to each of the three top bags so that all of the airbag volume could be acted upon during impact. This resulted in three ducts emerging from the bottom bag, each connecting to one of the top airbags.

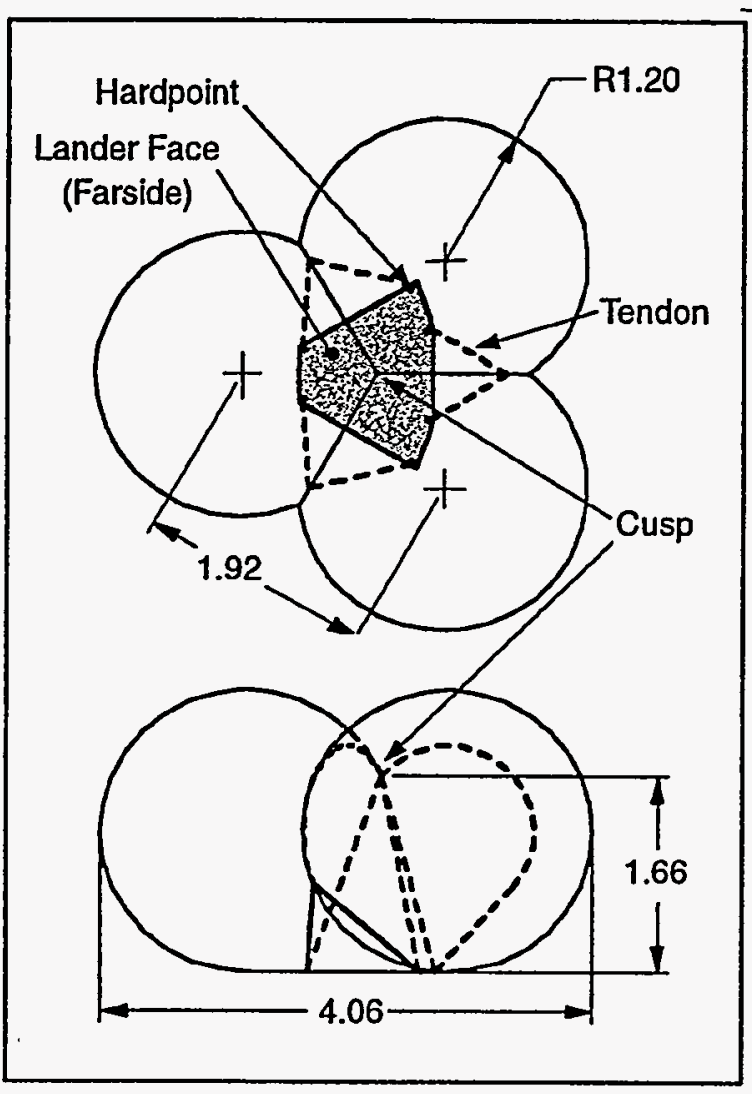

Figure 1 - Three-lobe airbag design

Further analysis of the difference between the constant deceleration profile assumption made earlier and more refined performance analyses showed that the $2.4 \mathrm{~m}$ diameter of the airbag was not sufficient to provide an adequate clearance margin for a nominal impact. This led to the second design enhancement: external venting. Controlled venting of the gas from the bottom bag to the ambient atmosphere allowed a higher initial pressure to be used without exceeding the deceleration requirement. The original venting scheme called for the maximum pressure condition to exist prior to impact. On impact the external vents would be permanently opened. The vents were sized so that the mass flow leaving the airbags matched the decrease in volume during an impact, thus yielding a nearly constant pressure profile.

An additional lightweight, gas-tight, internal diaphragm was installed in the bottom airbag (see figure 7). The diaphragm is inflated into the bottom bag by gas from the three top bags during the first bounce, halts the external venting, and insures that the airbag system remains inflated for subsequent bounces.

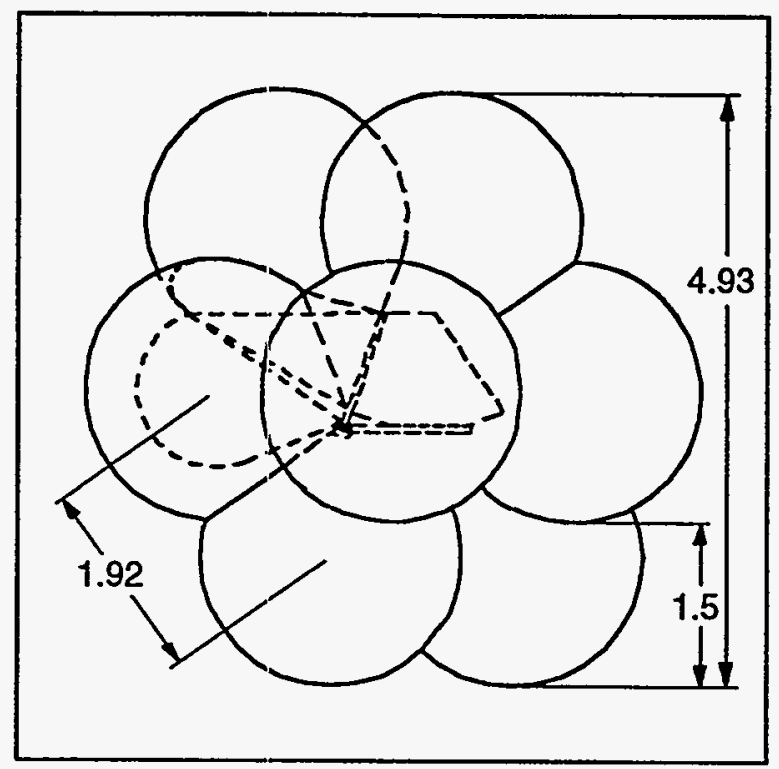

Figure 2 - Airbag system with lander

\section{Construction}

Polyurethane coated $3.0 \mathrm{oz} / \mathrm{yd}^{2}$ Kevlar fabric was selected for the proof of concept 0.38 scale prototype airbag (figure 3). The lobes were created by a

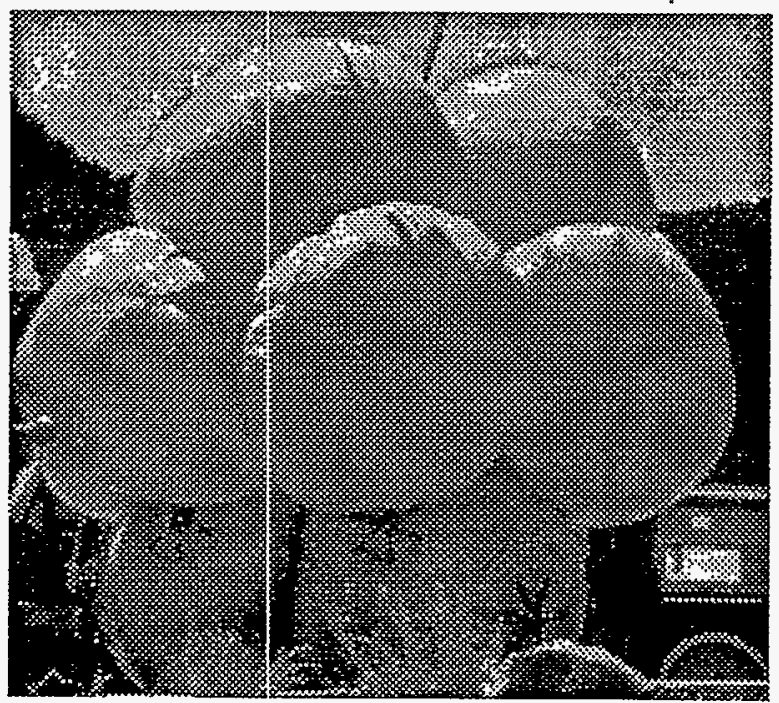

Figure 3 - First prototype airbag 
combination of fabric patterning and tensioning of the tendons anchored to the lander. The fabric patterns were joined using simple lap joint seams, formed by pressure fusion welding the urethane coating on the Kevlar fabric.

The airbag fabric was not directly attached to the lander at any location. As shown in figures 1 and 2, six tendons originate at each of six hardpoints on the lander, follow the external surface of the bag, and then pair up at a confluence point approximately $1 / 3$ the way around the bag. Three tendons then follow the valley between lobes up to the cusp. At the cusp, the tendons pass through the fabric and once again divide into six different tendons that pass through the fabric again and attach at each of the six hardpoints. The preload in the tendons, generated by the inflation pressure, transfers nearly all of the deceleration forces to the lander and are particularly important in transferring the shear force reactions during oblique impacts to the lander. Therefore, it was important to maximize the stiffness of the tendons. This was accomplished by using Kevlar, a high elastic modulus material.

\section{Second Generation Airbag Design}

Maturity of both the landing site location information and the entry and descent designs allowed a relaxation of the impact requirements. Both the maximum vertical and horizontal velocities expected at impact were reduced to $20 \mathrm{~m} / \mathrm{s}$. This allowed a redesign of the airbags to make them smaller and lighter. The new design was based on the same design principle as the original three-lobe design. The new design consists of six spheres meshed together to form a single airbag. The internal venting scheme was preserved. However, the external venting was no longer required to provide the necessary margins. Figures 4,5 , and 6 show the six-lobe configuration.

\section{Computer Modeling of the Airbag Impact Attenuation System}

A computer model was developed at Sandia to model the pneumatic performance of the airbags and the rigid-body dynamics performance of the payload during ground impact [2]. In Figure 7, it can be seen that the forces acting on the payload consist of the payload weight acting downward and the pressure force acting upward. Applying Newton's second law, the equation of motion for this system is obtained:

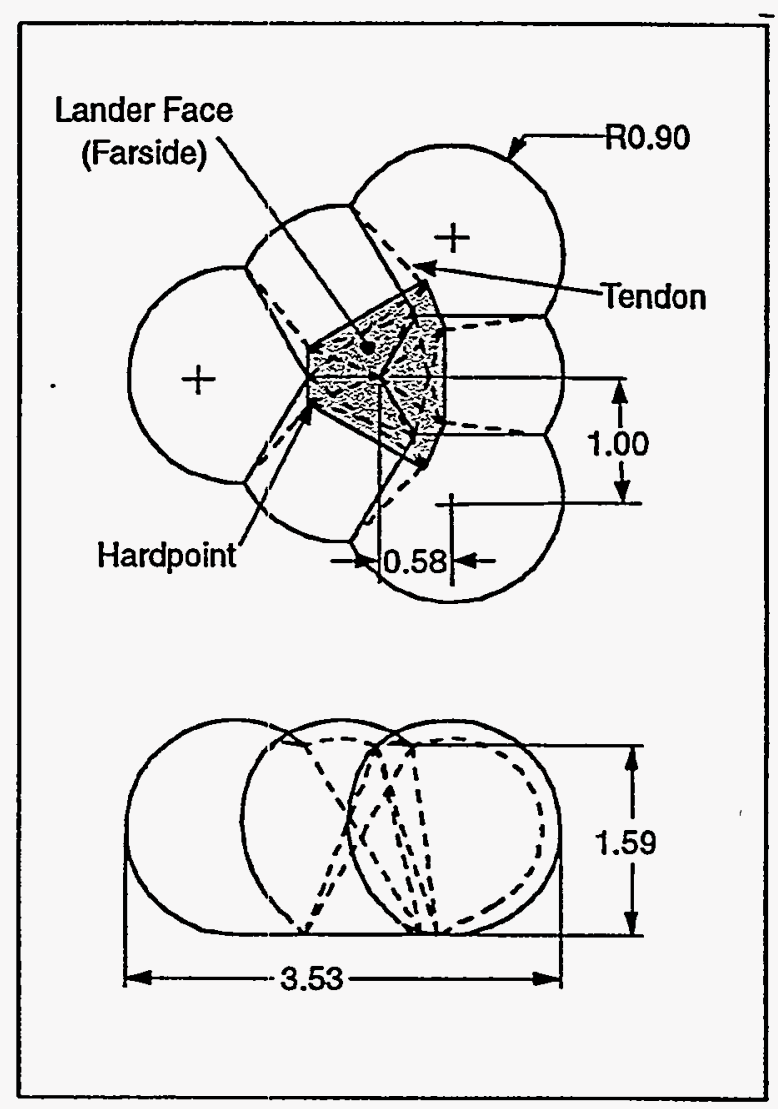

Figure 4 - Six-lobe airbag design

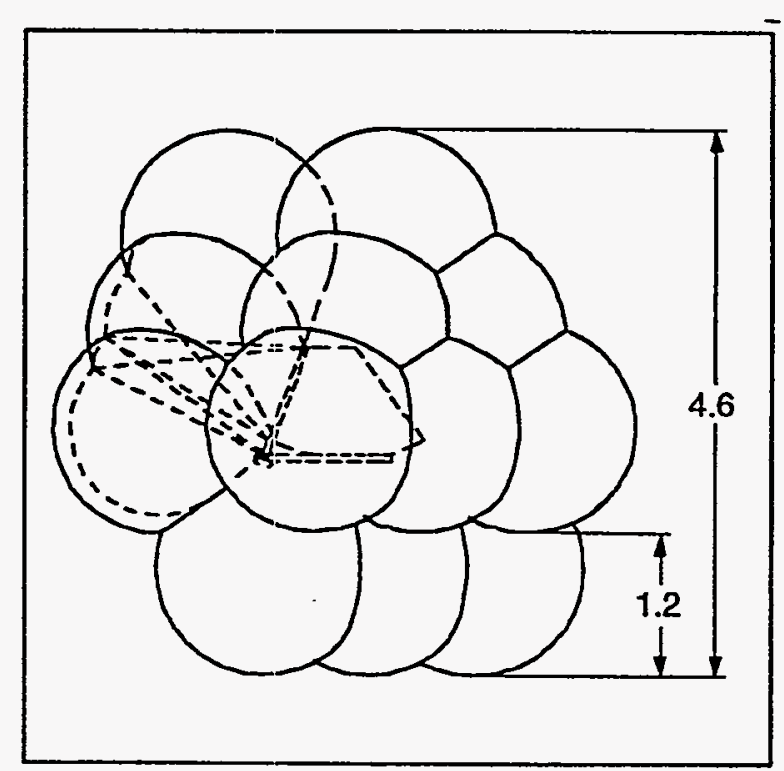

Figure 5 - Six-lobe airbags mounted to lander 


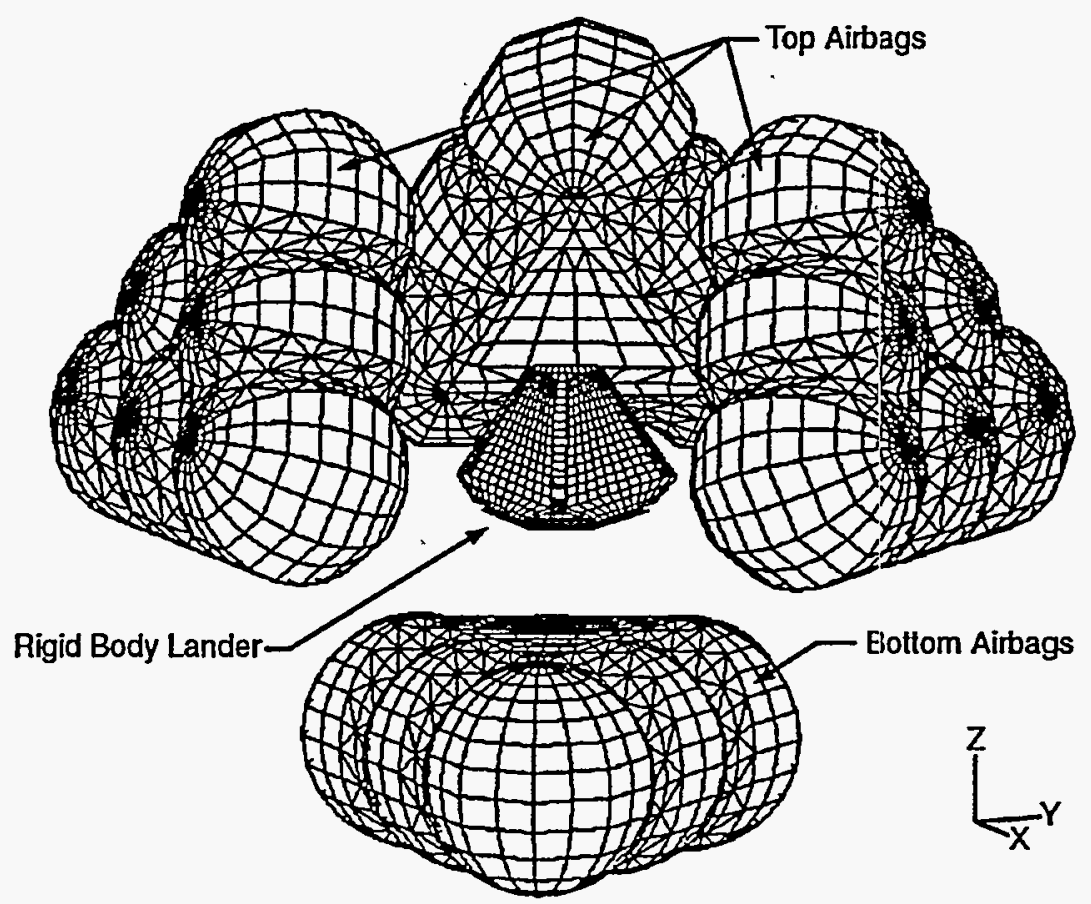

Figure 6 - Exploded view of Dyna-3D finite element model, six-lobe airbag design (Model created by Marc Collier and John McKinney of Rockwell Aerospace Space Systems Division)

$$
a=g_{\text {Mars }}-\frac{A_{F P} p_{o}}{m}\left(\frac{p_{b a g}}{p_{o}}-1\right)
$$

The nitrogen gas that was contained in all of the bags was assumed to perform as a perfect gas. The mass of gas contained in each bag was calculated from the known gas pressure, temperature, and bag volume.

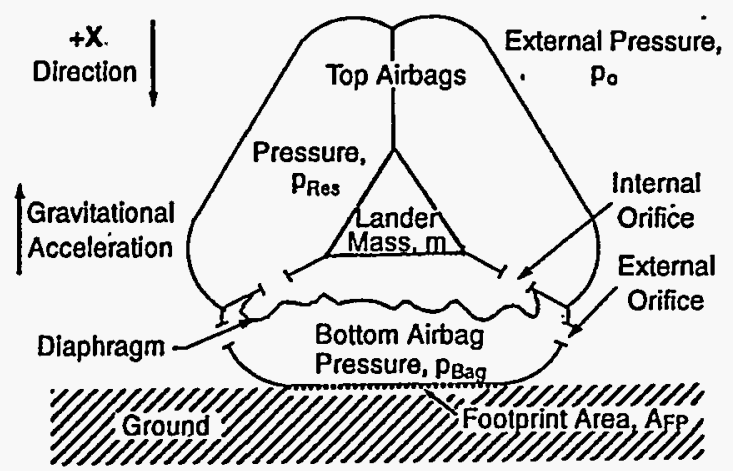

Figure 7 - Impact Attenuation System Sketch

Because all of the top bags communicated pneumatically with the bottom bag, the gas contained within them was assumed to be at the same pressure and temperature before impact. Just before impact, external orifices could be opened in the bottom bag and gas could start flowing out to the local environment from the bottom bag. At impact, the volume of the bottom bag began to decrease. If the external orifices were not too large, the gas pressure in the bottom bag would begin to increase forcing gas back into the top bags as well as to the outside. If the external orifices were too large, the pressure in the bottom bag would continue to decrease and the gas in the top bags would continue to flow into the bottom bag until the diaphragm expanded to fill the remaining volume of the bottom bag. At that time, gas would cease flowing from the external orifices.

Gas flow through an orifice can be subsonic or sonic depending on the static pressure ratio of the gas downstream to that of the gas upstream. For a diatomic gas, such as nitrogen, if the static pressure ratio is greater than 0.5283 , the flow is subsonic up to and through the smallest flow area, the orifice. If the ratio is smaller than 0.5283 , the flow is subsonic as it approaches, but sonic in the orifice [3].

To slow the impacting payload, its kinetic energy must be transferred into the potential energy of the compressed gas. Thus, the airbags must 
operate with an absolute internal pressure that is greater than the local atmospheric pressure to generate a force which, acting through the deflection of the bag, does work on the payload. An airbag impact attenuation system intended for use on Mars can be tested in the earth's atmospheric pressure with the intended initial pressure differential from the bag interior to the atmosphere, but the external orifices will not perform as they would on Mars since the pressure ratio across them is significantly different.

The mass of gas discharged through the external orifices and the mass of gas remaining in the bag directly affect the rebound of the payload, so an atmospheric test on earth would not exhibit the same initial rebound speed as would actually occur on Mars.

The mass flow rate at the orifice throat (subscript th) is:

$$
\frac{d W}{d t}=k A_{t h} \rho_{t h} u_{t h}
$$

The gas density at the throat of the orifice is:

$$
\rho_{t h}=\frac{p_{t h}}{\left(R_{G A S} T_{t h}\right)}
$$

and the gas velocity at the throat in terms of sonic conditions is:

where:

$$
u_{t h}=M_{t h} a_{t h}^{*}
$$

$$
a_{t h}^{*}=\sqrt{\gamma R_{G A S} T_{t h}} .
$$

When equations 3-5 are factored into equation 2 , the mass flow rate is expressed in terms of the pressure and temperature in the orifice throat.

$$
\frac{d W}{d t}=k A_{t h} p_{t h} M_{t h} \sqrt{\frac{\gamma}{R_{G A S} T_{t h}}} .
$$

Since the average gas flow within a bag is nearly zero, the static pressure and the stagnation pressure in the bag are essentially equal. Hence the static pressure in the orifice throat as a function of the pressure upstream of the orifice is [4]:

$$
\frac{p_{t h}}{p_{u}}=\left(1+\frac{(\gamma-1) M_{t h}^{2}}{2}\right)^{\frac{\gamma}{1-\gamma}} .
$$

When equation 7 is solved for $M$ and substituted along with the adiabatic equation into equation 6 , the equation for the mass flow rate through a subsonic orifice is obtained

$\frac{d W}{d t}=k A_{t h} p_{d}\left(\frac{1}{R_{G A S} T_{I}}\right)^{0.5}\left(\frac{2 \gamma}{\gamma-1}\left(\frac{p_{I}}{p_{d}}\right)^{\frac{\gamma-1}{\gamma}}\right)^{0.5}\left(\left(\frac{p_{u}}{p_{d}}\right)^{\frac{\gamma-1}{\gamma}}-1\right)^{0.5}$

For sonic flow in the orifice, $M=1.0$, and equation 7 reduces to:

$$
\frac{p_{t h}}{p_{u}}=\left(\frac{(\gamma+1)}{2}\right)^{\frac{\gamma}{1-\gamma}}
$$

Substituting the adiabatic equation and equation 9 into equation 6 and rearranging produces the equation for the mass flow through a sonic orifice.

$\frac{d W}{d t}=k A_{t h} p_{I}\left(\frac{1}{R_{G A S i} T_{I}}\right)^{0.5}\left(\eta\left(\frac{2}{\gamma+1}\right)^{\frac{\gamma+1}{\gamma-1}}\right)^{0.5}\left(\left(\frac{p_{u}}{p_{I}}\right)^{\frac{\gamma+1}{\gamma}}\right)^{0.5}$

\section{Discharge Coefficient}

Both equations 8 and 10 depend upon the value of the orifice discharge coefficient, $k$. Experiments have been performed [5] in which the pressure differential across a sharp-edged orifice was varied to obtain subcritical (subsonic) and critical (sonic) flow conditions. Experimental values of $\mathrm{k}$ measured as a function of the ratio of downstream to upstream pressure for the range from 0.0 to 1.0 were included in the model.

Each top bag can exchange gas only with the bottom bag through its internal orifices. The mass flow rate, $\mathrm{dW} / \mathrm{dt}$, is determined by equation 8 or 10 depending on whether the orifice flow is subsonic or sonic. If the pressure differential causes flow from the bottom bag into the three top bags, that flow rate is considered to be negative and the mass of gas in the top bags increases. 
The bottom bag can exchange gas with the three top bags through the internal orifices and also with the outside through the external orifices. Gas flow out of the bottom bag, whether through the internal or external orifices, is considered to be negative. Thus, flow into the top bags and to the atmosphere will decrease the mass of gas contained in the bottom bag.

\section{Change in Bottom Bag Area and Volume}

The airbags proposed for the lander were constructed of fabric and restrained with external and internal tendons so that each appeared to consist of three or more spherical bags merged together.

As shown in equation 1 , the force that acts to decelerate the payload depends directly upon the area of the footprint $\left(A_{\mathrm{FP}}\right)$ of the bag with the ground. The internal pressure in the bottom bag which is being crushed also depends directly upon the change in the bag's volume. Note that an implicit assumption made in developing the area and volume equations for each bag design was that the parts of the bottom bag not in contact with the ground did not move nor flex relative to the lander. The area of the footprint as a function of the bag crushup was calculated for each bag configuration based strictly upon the bag geometry and the area of the bag that would be intersected by the plane of the ground during crushup.

The computational technique used to solve for the bag crushup and pneumatic changes of the system were adopted from those described in reference 6.

\section{Bounce Equations}

Since the gas remaining in the bags after the payload has been successfully stopped is still at a pressure greater than the local atmospheric pressure, the payload experiences some rebound (bounce). The same governing equation which calculates the transfer of the payload's kinetic energy into potential energy stored in the compression of the gas also calculates the reverse transfer of energy from the gas to the payload. The maximum velocity for a rebound is achieved at the instant the airbag ceases to push on the payload. This occurs when the airbag has reinflated to its original shape or when the pressure in the bag reaches the local atmospheric pressure. The height of the bounce, assuming no aerodynamic drag, is found by simply equating the payload's kinetic energy at the start of the rebound with its potential energy at the top of the rebound.

\section{Modeling}

The feasibility of using airbags to cushion the lander payload during ground impact on Mars had to be proven through testing on Earth. A modeling study was made to determine what test conditions were required to obtain meaningful data.

The Buckingham Pi Theorem [7] states that the number of non-dimensional numbers required to define a problem is equal to the total number of variables minus the total number of dimensions involved. There are 19 variables and four dimensions; mass, length, time and temperature in this problem. Thus, 15 non-dimensional numbers are needed.

These non-dimensional numbers can be obtained in many ways that often seem somewhat arbitrary. Once generated, they can be modified by multiplication or division with any combination of the other non-dimensional numbers that are involved. In this case, the more complicated nondimensional numbers were chosen from the coefficients in the non-dimensional governing differential equations. Note that the product of the gas constant and the temperature was considered as one variable since they were the only ones in this problem that contained the dimension of temperature. Doing this did not affect the quantity of non-dimensional numbers required, because both the number of variables and the number of dimensions were decrease by one. Fifteen nondimensional numbers were obtained.

Let the system being tested on Earth be the "prototype", denoted by the subscript, $\mathrm{P}$, and the system that is to impact on another planet be the "full-scale system", denoted by the subscript, F. For the results of a prototype test to be very meaningful all of the prototype non-dimensional numbers must equal their counterparts for the full-scale. When this occurs the modeling is called "undistorted."

Assume that the geometric scaling factor between the prototype and the full-scale is:

$$
\lambda=\frac{\left(X_{o}\right)_{P}}{\left(X_{o}\right)_{F}}
$$


and that the pressure ratio between the prototype and the full-scale is:

$$
n=\frac{p_{P}}{p_{F}} .
$$

Then equating the non-dimensional numbers between the prototype and the full-scale produces the following relationships between the variables:

$$
\begin{array}{cl}
X_{P}=\lambda \cdot X_{F} & A_{P}=\lambda^{2} \cdot A_{F} \\
V_{P}=\lambda^{3} \cdot V_{F} & m_{P}=n \cdot \lambda^{3} \cdot m_{F} \\
W_{P}=n \cdot \lambda^{3} \cdot W_{F} & \gamma_{P}=\gamma_{F} \\
\left(R_{G A S} T\right)_{P}=\left(R_{G A S} T\right)_{F} & k_{P}=k_{F} \\
p_{P}=n \cdot p_{F} & t_{P}=\lambda \cdot t_{F} \\
U_{P}=U_{F} & a_{P}=\left(\frac{1}{\lambda}\right) \cdot a_{F}
\end{array}
$$

The last equation shows the relationship that must be preserved between all of the prototype and full-scale accelerations. Hence, for the modeling to be undistorted:

$$
g_{P}=\left(\frac{1}{\lambda}\right) \cdot g_{F}
$$

The gravitational acceleration for the prototype is that of Earth, and for the full-scale, that of Mars where the lander will impact. Therefore, the ratio of the gravitational acceleration between Earth and Mars prescribes the model scale, $\lambda=0.38$, for undistorted model testing in full Earth gravity.

The feature, $\mathrm{n}$, was added to the modeling equations to free the prototype mass from having to be exactly $\lambda^{3}$ times the full-scale mass. This proved useful during the design of the High Altitude Chamber impact apparatus and in the development of the test program parameters.

These modeling relationships also prescribe how the measurements made during prototype impact tests can be used to predict the full-scale impact on Mars. Full-scale velocities are equal to prototype velocities. Full-scale accelerations are $\lambda$ times prototype accelerations. If the same gas at the same initial temperature is used in the full-scale and prototype, then temperature variations will be the same between the full scale and prototype impacts.

\section{Prototype Airbag Test Program}

\section{High Altitude Cliamber Test Series \#1.}

A test series of the original design was performed in May 1993 in the Sandia High Altitude Chamber (HAC). The impact test apparatus shown in Figure 8 was clesigned, fabricated, and assembled in the HAC for these tests [8]. Because accelerating the airbag system itself was impractical in the limited space of the HAC the "ground" was accelerated into the stationary, inverted, lander/ airbag system, which was mounted on a strut. To perform a test the impact plate was elevated and attached to a restraining cable. After the pressure in the HAC was brought to test conditions the bungee cords were stretched to equal tension and the impact plate was released through initiation of an explosive cable cutter. The impact plate was then accelerated towards the stationary airbag system by the bungee cords. Just before impact the bungee cords went slack and the velocity of the impact plate was measured by an optical velocity trap. Instrumentation on the impact plate and in each of the airbags measured the deceleration and pressure-time history of the event [9].

The impact plate was designed for minimal mass, but still exceeded the scaled mass of the fullscale system by a factor of two. The scaling model therefore required that the pressures (both internal and external) be doubled to provide a suitable simulation of deceleration. The tests were performed at a pressure of $2.0 \mathrm{kPa}(0.290 \mathrm{psi})$ external pressure, about twice that of the Martian atmosphere. The airbags were tested with initial internal pressures of $8.0 \mathrm{kPa}(1.16 \mathrm{psi})$ and $12.0 \mathrm{kPa}(1.74 \mathrm{psi})$.

Eighteen impact tests were performed with variations in impact velocity (maximum of $20 \mathrm{~m} / \mathrm{s}$ ), external orifice areas, and internal orifice areas. The tests validated the mathematical computer model and demonstrated that the timing for external vent opening was critical. These tests also showed that due to the location of the external vents the opening of the vents was severely affected by the crushup of the bags and was not repeatable. A modified code that tailored the external orifice area as a function of stroke as measured in the video documentation was prepared and usecl to model the airbag system. Very good correlation between the simulation and the test data was obtained. 
The results of these tests indicated that the performance of the airbag system was marginal for protecting the lander to less than the $50 \mathrm{~g}$ deceleration limit without the external vents. A decision was made to add the retro-rocket system to the descent and landing system in lieu of the external vents. The retro-rocket system decreases the vertical velocity component and allowed the airbags to be decreased in size.

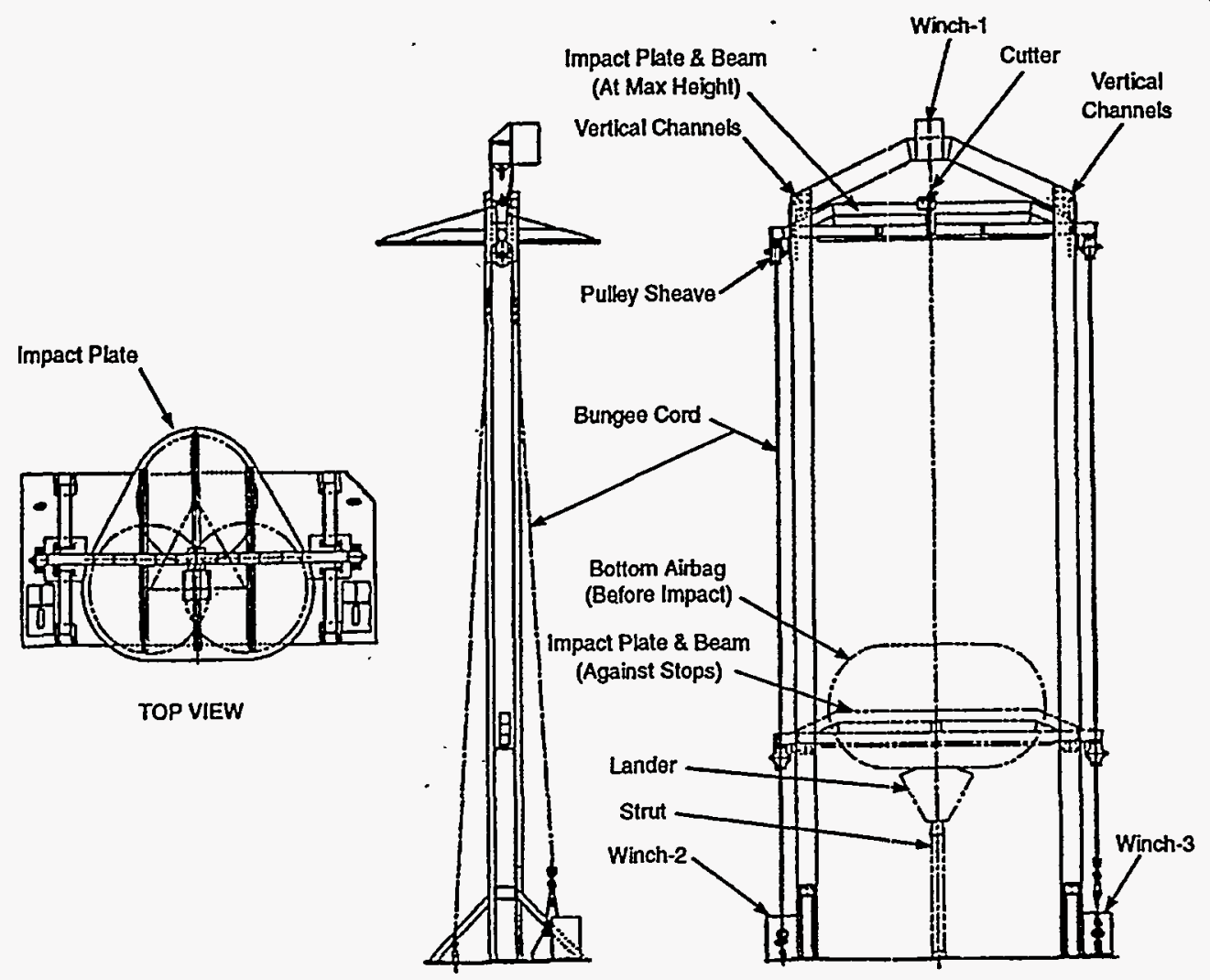

Figure 8 - Mars Impact Test Apparatus (top bags removed for clarity)

\section{Coyote Canyon Test Series}

A test series was required to evaluate the structural integrity of the airbag impact attenuation system and demonstrate system feasibility. Free fall drops of the system were needed at representative velocities to meet this requirement.

The Coyote Canyon Test Facility at Sandia National Laboratories, which consists of a cable suspended across a valley between two mountain ridges, was chosen as the site for this test series. The cable facility provides.a drop height of approximately 183 meter ( 600 feet) at the highest point above the valley floor. In the initial test series the airbags were dropped vertically from the cable. A $147 \mathrm{~kg}$ (325 lb) mass was attached to the bottom of the airbag system to accelerate the system to a desired impact velocity.
At impact the cable attaching the weight was severed so that the airbag system could rebound naturally.

The first terst of the system at $12 \mathrm{~m} / \mathrm{s}$ impact velocity was successful; however, the second $20 \mathrm{~m} / \mathrm{s}$ impact test caused substantial damage to the airbag structure. It should be noted, however, that the lander was still protected during this impact and did not exceed the $50 \mathrm{~g}$ deceleration limit. The two primary causes for the damage to the airbags were inadequate strain relief in the basic construction and faulty load paths at the tendon passthroughs. This problem was alleviated in the second prototype by creating a more direct tendon load path and by using nylon fabric locally around the passthroughs. The flight design is avoiding this problem completely by creating an enlarged inverted fabric boot to form the passthrough. The boot prevents any membrane loading in the vicinity of the hardpoint. 
The second prototype bag was tested with both vertical and horizontal components of velocity. This test was conducted by accelerating the airbag system down an inclined wire on a trolley designed by JPL. Five tests were conducted at velocities up to $25.6 \mathrm{~m} / \mathrm{s}$ total velocity. For the last test, a simulated Martian rocky surface was prepared. The airbags and lander survived all of these tests with the only damage being a four-inch tear in the fabric on the final test. Figure 9 shows an impact sequence from these tests.

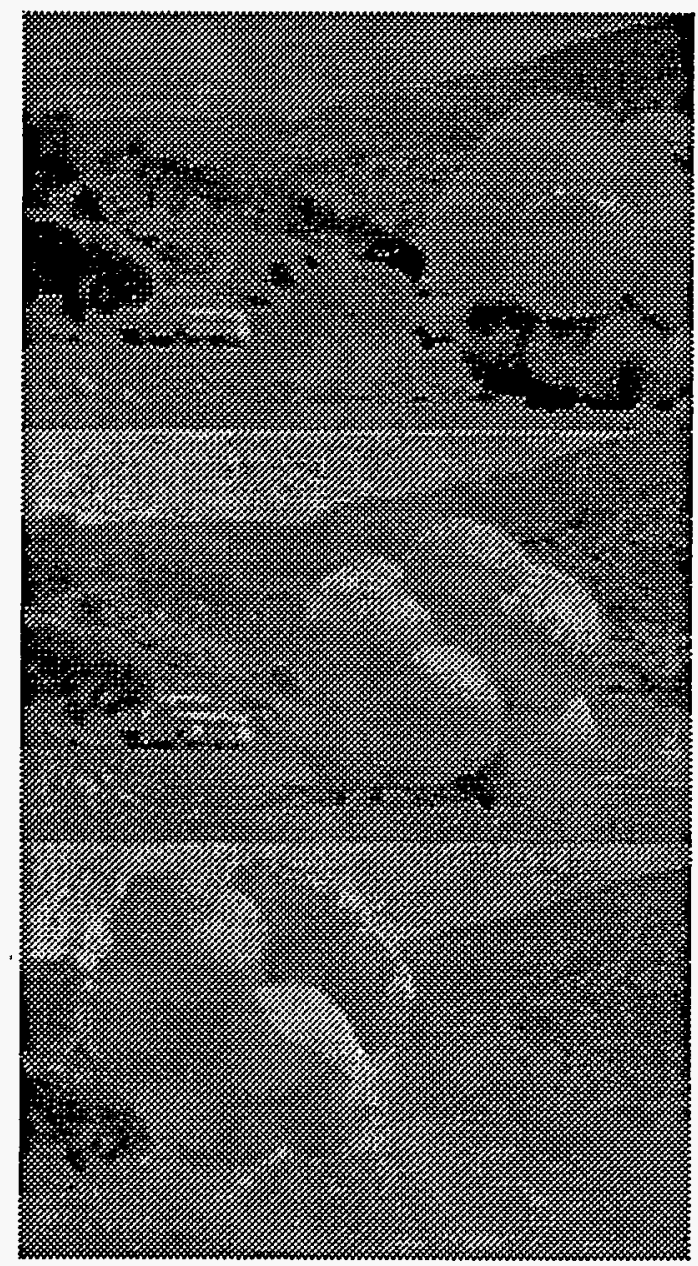

Figure 9 - Canyon Test Airbag Impact

\section{HAC Test Series \#2.}

A second HAC test series was conducted in mid-September 1994. The purpose of this series was to demonstrate performance of the second generation airbag design under the same conditions as the original design and to validate the mathematical predictions used to size and design this second generation system. One of the major performance parameters investigated in this test series was the size of the internal orifices. The computer model pre- dicts an optimal size that minimizes the deceleration and also the rebound. In addition, tests were conducted to demonstrate performance of the airbags when impact occurs on a top bag or on three bags at an apex.

The same inpact apparatus used for the first test series in the HAC was reused for this series of tests. In addition, a tripod stand was constructed to support the lander/airbag system with an apex pointed upward. This allowed investigation of an impact on the "apex" of the airbags where the footprint area impacting the ground is smallest.

The impact test results were then compared to the computer model. The results were not consistent with the computer model; however, examination of the test video showed that flexing of the airbags invalidated one of the code assumptions. A pneumatic volume module was added to the code to compensate for the main bag flexing below the original bottom plane of the lander. Also the footprint area and volume of the impact bag were calculated from the impact data and inserted into the computer model. These data more accurately modeled the area and volume of the system as it flexed away from the impact plate. Finally, the flow through the internal orifices of the second generation airbags did not appear to be properly modeled by a sharp edged orifice. A constarit flow coefficient of 0.98 was used to model this flow. This modified code more accurately models the impact attenuation system results. Figures 10 and 11 illustrate the bottom bag pressure and deceleration test data and the code simulation curve.

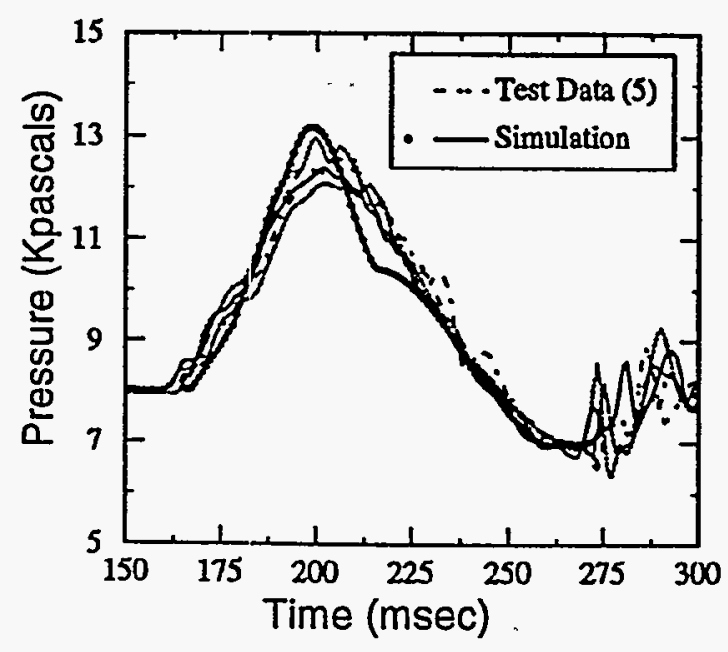

Figure 10 - Pressure versus Time 


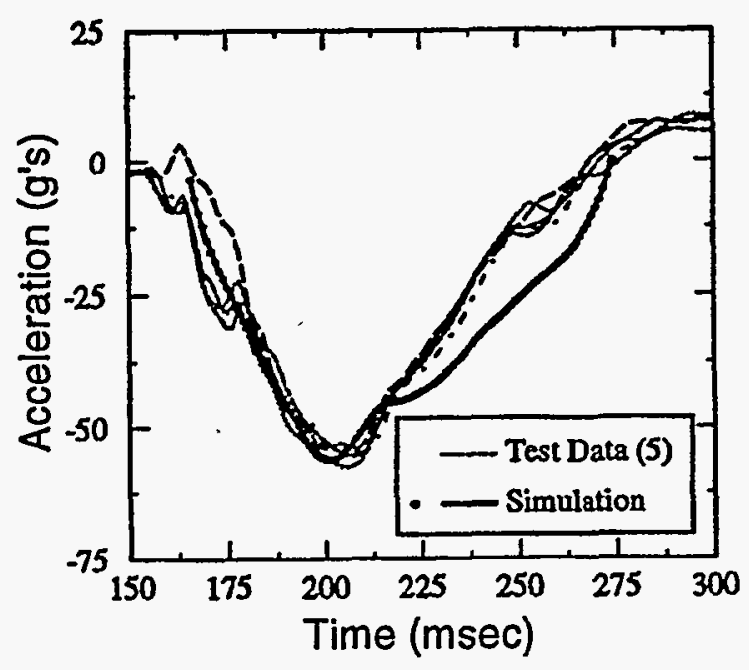

Figure 11 - Acceleration vs. Time

\section{Flight System Testing}

The test program described in this paper was considered proof of concept work to demonstrate the feasibility of using an airbag system for a planetary lander. In support of the flight article to be sent to Mars, JPL and ILC Dover Inc. have designed and are performing a much more extensive and detailed series of tests. These tests are all conducted with full scale airbags under Mars pressure conditions. The tests include, but are not limited to; retraction testing, rapid inflation testing at Mars temperature and pressure, and full speed drop testing onto a $60^{\circ}$ slanted platform with 0.5 meter high rocks. The results of these tests will validate and qualify the flight airbag and gas generator designs.

\section{Conclusions and Recommendations}

An impact attenuation system for the Mars Pathfinder spacecraft has been designed, a prototype 0.38 scale model fabricated, a computer model prepared, and tests conducted. This feasibility program has demonstrated that the Airbag Impact Attenuation design will protect the Mars Pathfinder lander upon impact with the Martian surface. A contract for the flight test bag fabrication and demonstration program has been issued to $\mathrm{ILC}$ Dover Inc. as part of the preparations for the November 1996 launch.

The computer code developed and validated for performance of the airbag system provides a tool for investigating performance of the full-scale system in the Martian environment. Parametric studies can be performed to investigate variations in impact velocity, internal and external pressure, internal vent areas, and lander mass. Also, modifications to the airbag system geometry can be investigated by changing the area and volume inputs in the code. The computer codle is currently limited, however, to investigation of vertical impacts on the bottom bag.

\section{Acknowledgments}

The authors wish to acknowledge the contributions and support of Bob Croll, John Henfling, Don McKenzie, and Ed Clark for the High Altitude Chamber test; Ed Constantineau for the design and fabrication of the impact apparatus; Larry Whinery and Dan Luna for fabrication of the prototype airbags; and Mark Garrett and Jim Calderone for the Coyote Canyon test series.

\section{References}

[1] Ross, R.G. Jr., Layman, W.E., The Design and Testing of an Inflated Sphere Impact Limiter, NASA TR No 32-1037, December 15, 1966.

[2] Cole, J. K. and Waye, D. E., BAG: A Code for Predicting the Ferformance of a Gas Bag Impact Attenuation System for the PATHFINDER Lander, Sandia National Laboratories, Albuquerque, NM, SAND93-2133, November 1993.

[3] Liepmann, H. W. and Roshko, A, Elements of Gas Dynamics, John Wiley \& Sons, 1957.

[4] Ames Researcli Staff, Equations, Tables and Charts for Compressible Flow, National Advisory committee for Aeronautics, Ames Aeronautical Laboratory Report 1135.

[5] Perry, J. A., Jr., Critical Flow Through Sharp-Edged Orifices, Transactions of the American Society of Mechanical Engineers, October 1949, pp. 757-764.

[6] Esgar, Jack B. and Morgan, William C., Analytical Study of Soft Landings on Gas-Filled Bags, NASA Lewis Research Center, Cleveland, OH, Technical Report R-75, March 16, 1960.

[7] Murphy, Glenn, Similitude in Engineering, The Ronald Press Company, New York, NY, 1950.

[8] Cole, J. K., Waye, D. E., Croll, R. H., and Constantineau, E. J., An Apparatus for Testing the PATHFINDER Lander Gas Bag Impact Attenuation System, Sandia National Laboratories, Albuquerque, NM, to be published.

[9] Clark, E. L., "Data Acquisition, Conversion, and Analysis for the MESUR Pathfinder High Altitude Chamber Test, 1994," Sandia National Laboratories, Albuquerque, NM, in possession of author. 